\title{
Multifunctional Actions of
} Ninjinyoeito, a Japanese Kampo Medicine: Accumulated Scientific Evidence Based on Experiments With Cells and Animal Models, and Clinical Studies

\author{
Kanako Miyano ${ }^{1}$, Miki Nonaka ${ }^{1}$, Miaki Uzu ${ }^{1}$, Kaori Ohshima ${ }^{1,2}$ and Yasuhito Uezono ${ }^{1,3,4,5 *}$ \\ ${ }^{1}$ Division of Cancer Pathophysiology, National Cancer Center Research Institute, Tokyo, Japan, ${ }^{2}$ Faculty of Pharmaceutical \\ Sciences, Tokyo University of Science, Chiba, Japan, ${ }^{3}$ Division of Supportive Care Research, Exploratory Oncology Research \\ and Clinical Trial Center, National Cancer Center, Tokyo, Japan, ${ }^{4}$ Innovation Center for Supportive, Palliative and \\ Psychosocial Care, National Cancer Center Hospital, Tokyo, Japan, ${ }^{5}$ Department of Comprehensive Oncology, Nagasaki \\ University Graduate School of Biomedical Sciences, Nagasaki, Japan
}

OPEN ACCESS

Edited by:

Akio Inui,

Kagoshima University, Japan

Reviewed by:

Hiroshi Takeda

Hokkaido University, Japan Atsushi Fukao,

Ibaraki City Health and Medical

Center, Japan

*Correspondence:

Yasuhito Uezono

yuezono@ncc.go.jp

Specialty section:

This article was submitted to

Clinical Nutrition,

a section of the journal

Frontiers in Nutrition

Received: 25 July 2018

Accepted: 19 September 2018

Published: 08 October 2018

Citation:

Miyano K, Nonaka M, Uzu M, Ohshima K and Uezono Y (2018) Multifunctional Actions of Ninjinyoeito,

a Japanese Kampo Medicine:

Accumulated Scientific Evidence Based on Experiments With Cells and Animal Models, and Clinical Studies.

Front. Nutr. 5:93.

do: 10.3389/fnut.2018.00093
Herbal medicines are currently employed for the treatment of several types of diseases, and also employed for the improvement of Quality of Life (QOL) of patients over the world, in particular, in Asian countries. In Japan, a Japanese herbal medicine namely kampo medicine has been prescribed for the improvement of QOL of patients. Ninjinyoeito (NYT), composed of 12 herbal plants, is one of kampo medicines and used for helping recovery of diseases and improving several symptoms that suffer patients such as anemia, anorexia and fatigue. Recent scientific research approaches to kampo medicines with cells and animal models enable to prove that NYT has multiple functions for improvement of symptoms. Also, clinical studies using NYT support such actions to be widely used for the improvement of symptoms that reduce the QOL of patients.

Keywords: herbal ingredient, kampo medicine, Ninjinyoeito, mixed ingredients, scientific evidence

\section{INTRODUCTION}

Ninjinyoeito (NYT) is a Japanese herbal medicine prescribed and clinically admired in Japan. NYT has multi-functional beneficial activities so that it is used for improvement of recovery from diseases or some symptoms (1-7). Further, NYT has been reported to have antiviral action on hepatitis C virus (HCV), antioxidant and immuno modulatory effects $(8,9)$. NYT is composed of 12 crude ingredients, including Rehmannia root, Japanese angelica root, Atractylodes rhizome, Poria sclerotium, Ginseng, Cinnamon bark, Polygala root, Peony root, Citrus unshiu peel, Astragalus root, Glycyrrhiza, and Schisandra fruit.

Recent scientific approaches to analyze the mechanism of action of kampo medicine including NYT enable to understand how kampo medicines act on patients and their functional sites of action (10-12). Further, understanding of the mechanism of action for each herbal ingredient composed of NYT help the mechanism of action of NYT. In this review, we introduce multifunctional actions of NYT by showing accumulated scientific evidence based on experiments with cells and animal models and also clinical studies using NYT. 


\section{ACTIONS OF NYT FOR THE IMPROVEMENT OF DISEASES OR SYMPTOMS}

Because of multi components of NYT, NYT has a variety of sites of action so that it is widely used for improvement of several types of symptoms, as follows.

\section{Contribution of NYT to Improve Neurodisorder}

NYT has been postulated to contribute of improvement of symptoms of Alzheimer's disease patients (13). In an experiment with rat embryo astrocytes, Yabe reported that NYT and its constituent onjisaponins contained in the roots of polygala tenuifolia significantly elicited nerve growth factor (NGF) secretion, a neurotrophic peptide (14). NGF is well known to be associated with the development and maintenance of cholinergic neurons in basal forebrain (15).

Sato demonstrated that the $\gamma$ chain of immunoglobulin Fc receptor $(\mathrm{FcR} \gamma)$ and Fyn protein tyrosine kinase (Fyn) signaling cascade is critically involved in cuprizone-induced demyelination without any lymphocytic response with a model for certain human demyelinationing disorders (4). They showed in the model that NYT administration recovered the demyelination in cuprizone-treated mice, and also showed the site of action of NYT is the FcR $\gamma$ Fyn-Rho (Rac2)-p38 mitogen-activated protein kinase phosphorylated myelin basic protein signaling, which is working in the myelination process (4).

With olfactory bulb lesions injured by Zinc sulfate perfusion, Song investigated the effects of NYT on brain monoamine and NGF (16). They showed the reductions of dopamine and its metabolites, 5-HT and its metabolite in olfactory bulb, hippocampus and substantia nigra in the model, and NYT inhibited the reduction. As a result, NYT consequently recovered the learning and memory lowered by Zinc sulfate perfusion (16).

\section{Myelopoiesis and Erythropoiesis}

Hematopoiesis is the process whereby functional, mature hematopoietic cells (red blood cells (RBCs), leukocytes, and platelets) are generated from hematopoietic stem cells in bone marrow (BM). Erythropoiesis, one aspect of hematopoiesis in which erythroid progenitors, such as burst forming unit-erythroid (BFU-B) and colony forming uniterythroid (CFU-E) cells, is initially generated and then gives rise to erythroblasts, reticulocytes, and finally RBCs, which contain hemoglobin functioning in oxygen transport $(17,18)$. Failure of erythropoiesis results in a shortage of or damage to RBCs and underlies anemia. NYT has been reported to overcome anemia resulting from anticancer therapies in humans (1). In mice treated with an anticancer drug 5fluorouracil (5-FU) and received anemia due to 5-FU, oral administration of NYT protected against hematotoxicity and induced immature erythroid progenitor cells. Also, oral administration of NYT improved 5-FU-induced anemic conditions, determined by measurement of reticulocyte and RBC numbers, hemoglobin and hematocrit levels in peripheral blood, and increases in BFU-E and CFU-E in BM in mice (3).

\section{Modulation of Immunoresponses}

Takaku reported that NYT enhanced synergistically the antitumor vaccine effects induced by $\mathrm{CD} 8^{+} \mathrm{T}$ cells. They demonstrated that NYT is a useful adjuvant herbal medicine for cancer immunotherapy (6).

Multiple myeloma (MM) is an incurable malignancy of plasma cells and includes the involvement of chemokines, cytokines and growth factors secreted from MM (19). For these patients over 65 years, Melphalan-prednisone (MP) therapy has been employed (5). In this study, MP treatment lowered the concentrations of several cytokines such as RANTES, sE-selectin, but not Ang-2 and VEGF. When treated together with NYT, it enhanced MP-associated reduction and also reduced Ang-2 and VEGF. During this combination therapy, immunoglobulin concentrations were significantly improved and improved general fatigue of patients, suggesting beneficial immunotherapeutic effects of NYT on MM patients (5).

\section{Neuropathic Pain}

NYT has been reported to have anticytotoxic activities. In neuron-like pheochromocytoma PC12 cells, an antitumor drug oxaliplatin induced neurodegeneration. With this model, NYT was found to prevent the neurodegenerative effects by oxaliplatin (20). Further, in mice model, the same authors reported that NYT and its gradient ginseng, in particular, ginsenoside $\mathrm{Rg}_{3}$, suppressed oxaliplatin-induced neurite damage and neuropathic pain (7).

\section{Scavenging Action of NYT on Several Types of Free Radicals}

NYT has been reported to have scavenging activity of several types of radicals including 1,1-diphenyl-2-picrylhydrazyl (DPPH) radicals in in vitro system as well as ascorbic acid and $\alpha$-tocopherol (8). They proposed that examination of radical scavenging ability of kampo medicines is a better method for evaluating the efficacy of kampo medicines (8). Actually, Hange-shasinto, a kampo medicine that is widely prescribed for therapeutic use of oral stomatitis, has been reported to have radical scavenging effects in six out of seven herbal ingredients consisting of Hange-shasinto (21).

\section{Frailty in Locomotor Disease}

Frailty is a syndrome that includes broad problems of senility and consists of three domains: physical, psychological, and social. Kampo medicines are used for intervention in cases of hypofunction in a mental or physical state (22). For frailty, NYT is useful in patients with symptoms of coldness or cutaneous dryness. NYT demonstrates hematopoietic activity and is effective for osteoporosis management (22). Also, NYT was effective for anorexia of aging in Alzheimer's disease (23). 


\section{ACCUMULATED EVIDENCE OF THE EFFECTS OF EACH HERBAL PLANTS CONSISTING OF NYT}

Here we show the effects of each herbal ingredient that consist of NYT, as follows (Table 1).

\section{Rehmannia Root}

Rehmannia root has been reported to have antiosteoporotic and neuroprotective effects $(25,26)$. Catalpol, the main component in Rehmannia root, inhibited ischemia-induced promyelinating oligodendrocyte damage by the regulation of intracellular homeostasis through $\mathrm{Na}^{+} / \mathrm{Ca}^{+}$exchanger 3 activity (27). Also, catalpol reduced insulin resistance caused by high-fat diet and inflammation of adipose tissues by the inhibition of the c-Jun
$\mathrm{N}$-terminal kinase and nuclear factor- $\kappa$ B-induced signaling (24). Catalpol is presented as a potential therapeutic for neurodegenerative diseases (25).

\section{Japanese Angelica Root}

Japanese angelica root contains many of bioactive components. One of main components is ligustilide (30). Ligustilide has antiinflammatory and antinociceptive effects $(28,29)$. Qian reported that ligustilide ameliorated pain caused by inflammation and inhibited TLR4 upregulation in spinal astrocytes induced by injection of complete Freund's adjuvant (30).

\section{Atractylodes Rhizome}

For atractylenolide I (ATR) in Atractylodes rhizome, a pilot randomized study $(n=11)$ of ATR on cachexia patients with

TABLE 1 | Physiological functions of basic components from each ingredients in NYT.

\begin{tabular}{|c|c|c|c|c|c|}
\hline & Herbal ingredients & Formula in NYT & Basic components & Physiological functions & References \\
\hline 1 & Rehmannia Root & $4.0 \mathrm{~g}$ & catalpol & $\begin{array}{l}\text { - Antiosteoporotic } \\
\text { - Antineurodegenerative } \\
\text { - Regulation of } \mathrm{Na}^{+} / \mathrm{Ca}^{2+} \text { exchanger } 3\end{array}$ & $(24-27)$ \\
\hline 2 & Japanese Angelica Root & $4.0 \mathrm{~g}$ & ligustilide & - Antiinflammatory & $(28-30)$ \\
\hline 3 & Atractylodes Rhizome & $4.0 \mathrm{~g}$ & atractylenolides & - Improve symptom of cancer patients & (31) \\
\hline 4 & Poria Sclerotium & $4.0 \mathrm{~g}$ & pachymic acid & $\begin{array}{l}\text { - Antitumor } \\
\text { - Inhibition of enzymes from acyl ghrelin } \\
\text { (active) to des-acyl ghrelin (inactive) }\end{array}$ & $(32-37)$ \\
\hline 5 & Ginseng & $3.0 \mathrm{~g}$ & ginsenoside & $\begin{array}{l}\text { - Antitumor } \\
\text { - Antiinflammatory } \\
\text { - Antioxidative }\end{array}$ & $(7,38-41)$ \\
\hline 6 & Cinnamon Bark & $2.5 \mathrm{~g}$ & cinnamaldehyde & $\begin{array}{l}\text { - Antiinflammatory } \\
\text { - Antioxidative } \\
\text { - Antitumor } \\
\text { - Neuroprotective }\end{array}$ & $(42-46)$ \\
\hline 7 & Polygala Root & $2.0 \mathrm{~g}$ & tenuigenin & $\begin{array}{l}\text { - Neuroprotective } \\
\text { - Antiinflammatory }\end{array}$ & $(47-49)$ \\
\hline 8 & Peony Root & $2.0 \mathrm{~g}$ & paeoniflorin & $\begin{array}{l}\text { - Pain relief } \\
\text { - } \mathrm{Ca}^{2+} \text { channel inhibition }\end{array}$ & $(50-52)$ \\
\hline 9 & Citrus Unshiu Peel & $2.0 \mathrm{~g}$ & hesperidine, hesperetin & $\begin{array}{l}\text { - Neuroprotective } \\
\text { - Antioxidant } \\
\text { - Antiinflammatory }\end{array}$ & $(53-56)$ \\
\hline 10 & Astragalus Root & $1.5 \mathrm{~g}$ & astragaloside, isoastragaloside & $\begin{array}{l}\text { - Elevation of adiponectin production } \\
\text { - Antitumor }\end{array}$ & $(57-60)$ \\
\hline 11 & Glycyrrhiza & $1.0 \mathrm{~g}$ & glycyrrhizin, glycycoumarin & $\begin{array}{l}\text { - Antiinflammatory } \\
\text { - Antioxidative } \\
\text { - Neuroparotective } \\
\text { - Keep ghrelin levels as pachimic acid }\end{array}$ & $(32,61,62)$ \\
\hline 12 & Schisandra Fruit & $1.0 \mathrm{~g}$ & schizandrin & $\begin{array}{l}\text { - Antiinflammatory } \\
\text { - Enhancement of skeletal muscle } \\
\text { endurance }\end{array}$ & $(63-65)$ \\
\hline
\end{tabular}


gastric cancer showed ATR was significantly more effective than fish-oil-enriched nutritional supplementation in improving appetite and Karnofski performance status, suggesting ATR might be beneficial in alleviating cachexic symptoms in gastric cancer patients (31).

\section{Poria Sclerotium}

Poria sclerotium has a long history as a herbal medicine and a wild spectrum of pharmacological activities such as antitumor, antioxidant, antiinflammatory effects (33). Pachymic acid, one of the main components of Poria sclerotium, has been reported to have antitumor effects to several types of tumor cells (34-37). On the other hand, Rikkunshito, a kampo medicine prescribed for gastrointestinal disorders, enhances orexigenic ghrelin-mediated signaling $(10,12)$. Acyl ghrelin is the active hormone and it degrades inactive form of des-acyl ghrelin by ghrelin deacylating enzymes (32). Pachymic acid in Poria sclerotium as well as glycycoumarin in Glycyrrhiza and 10-gingerol in Ginger inhibited this enzyme activity and kept circulating acyl ghrelin levels, thus maintaining the effect of ghrelin (32). NYT contains both Poria sclerotium and Glycyrrhiza, suggesting these two ingredients may involve the ghrelin-mediated signaling in NYT (12).

\section{Ginseng}

Ginseng has a wide range of pharmacological activities including antitumor, antiinflammatory, antioxidative and inhibition of cardiovascular diseases $(40,41)$. Further, the extract of Ginseng $\left(\mathrm{Rg}_{3}\right)$ showed a protective effect against neurite damage induced by oxaliplatin (7). Ginseng extracts partially relieved oxaliplatininduced neuropathic pain (7). In the effect to central neurons system, many of studies suggest ginseng causes improvement in memory and learning in the aged or damaged brain in rats (38). Also, ginsenoside- $\mathrm{Rg}_{2}$ from Panax ginseng protected memory impairment through antiapoptosis with a rat model having vascular dementia (39).

\section{Cinnamon Bark}

Cinnamon bark is widely used in food and traditional herbal medicine including NYT. Cinnamon has been reported to elicit diverse biological functions such as antiinflammatory (42) antioxidant (43), antimicrobial (43), and antitumor activity (44). A recent report showed that cinnamaldehyde has potent neuroprotective effects against oxidative stress and apoptosis induced by glutamate with rat pheochromocytoma PC12 cell as a neuron model (45). As for antioxidative effect of cinnamon bark, Sedighi recently reported that the extract of cinnamon bark with ethanol could protect the heart injured by ischemia-reperfusion probably because of its antioxidant properties (46).

\section{Polygala Root}

Tenuigenin in Polygala root has been reported to have neuroprotective effects. For example, it promoted hippocampal neural stem cell proliferation and differentiation (48) and it also has protective effects in cultured hippocampal neurons (47). Furthermore, tenuigenin has antiinflammatory effects and it inhibited lipopolysaccharide-induced inflammatory responses in microglia via activating the Nuclear factor E2-related factor 2-mediated heme oxygenase 1 signaling pathway (49).

\section{Peony Root}

Products from Peony root have been used for pain relief (52) and antispasmodic (51). Paeoniflorin, a glycoside isolated from Peony root, is reported to inhibit L-type $\mathrm{Ca}^{2+}$ currents in neuroblastoma NG108-15 cells (50). These effects may partially explain paeoniflorin or Peony root to cause neuronal or neuroendocrine inhibitory effects as well as pain relief (50).

\section{Citrus Unshiu Peel}

A flavonoid hesperetin in Citrus unshiu peel is reported to have a variety of biological activities, including anticancer, antiviral, antioxidant, neuroprotective and antiinflammatory properties (55). For example, hesperidin ameliorates cognitive dysfunction, oxidative stress and apoptosis against aluminum chloride induced rat model of Alzheimer's disease (56). Administration of citrus unshiu peel is reported to reverse age-induced demyelination (54). Also, restoration of $\mathrm{FcR} \gamma / \mathrm{Fyn}$ signaling activated by citrus unshiu peel repaired central nervous system demyelination (53).

\section{Astragalus Root}

Main components in Astragalus root are astragaloside and isoastragaloside. $\mathrm{Xu}$ reported that astragaloside and isoastragaloside in Astragalus root by screening of 50 medical herbs elevated circulating adiponectin levels by enhancing adiponectin production in mouse adipocytes (60), a well-known hormone to reduce risk of obesity, cardiovascular, and diabetic pathophysiology $(57,58)$. Also, Astragalus extract was reported to inhibit destruction of gastric cancer cells to methothelial cells by antiapoptosis, suggesting that Astragalus root can be used an adjuvant chemotherapeutic agent in gastric cancer therapy (59).

\section{Glycyrrhiza}

Glycyrrhiza extracts such as glycyrrhizin has been reported to have a variety of biological activities such as antiinflammation, anticancer, antioxidative, antiviral, antimicrobial effects as well as neuroprotective and immunomodulatory effects $(61,62)$. Also, as mentioned in the above section of Poria sclerotium, glycycoumarin in Glycyrrhiza inhibited circulating deacylating enzymes to consequently enhance the ghrelin-mediated signaling (32).

\section{Schisandra Fruit}

Schisandra fruit has many of bioactive activities. Kim reported that its extracts improved endurance and energy metabolism by upregulation of proliferator-activated receptor $\gamma$ coactivator$1 \alpha$ (PGC-1 $\alpha)$ in the skeletal muscle of exercised rats (64). Moon reported schizandrin, a main component of Schisandra fruit had antiinflammatory effects and it could be useful for the inflammatory and atopic diseases (63). Further, schizandrin B, an extract from Schisandra fruit ameliorated the lipopolysaccharide-induced depressive-like behaviors by attenuation of inflammation in the hypothalamic paraventricular nucleus and central nucleus of the amygdala in mice (65). 


\section{CLINICAL STUDIES USING NYT}

Although not so many, clinical studies regarding the effects of NYT on healthy human or patients have been conducted. Clinical reports showed that BT-11, the extract of dried roots of Polygala that is ingredient of NYT, had memory-enhancing effects in a randomized, placebo-controlled and double-blind study of BT-11 in healthy adults (66). The extract is also reported to have enhancing effects in cognition in elderly humans in a randomized, placebo-controlled and double-blind study (67).

In clinical study with Alzheimer's patients (23 patients) over 2-year period, two groups between donepezil (11 patients) and donepezil with NYT (12 patients) treatment were compared and assessed. Tests performed included Mini-Mental State Examination and the Alzheimer's Disease Assessment Scalecognitive component-Japanese version for cognitive function (13). Further, the Neuropsychiatric Inventory was used to evaluate the patients' mood status at baseline and every 6 months for 2 years (13). Authors demonstrated that A 2-year followup of patients receiving donepezil with NYT treatment showed an improved cognitive outcome and alleviation of Alzheimer's disease-related depression, judged from several tests mentioned (13). Further, an open-label pilot study with frail Alzheimer's disease patients showed that NYT could be a new-type dementia therapeutic agent with low risk of adverse effects, which improves anorexia, apathy, and cognitive dysfunction (23).

Nowadays, complementary and alternative medicine such as traditional Chinese medicines and Japanese kampo medicines is frequently used together with western medicines for treatment of diseases including chronic kidney diseases (68). In an openlabel clinical study, Hsiao reported that NYT could decrease chronic inflammation and increase QOL in 59 (27 NYT and 32 control) patients treated with hemodialysis due to chronic kidney diseases (68). In addition, a randomized controlled trial with NYT was conducted in patients receiving ribavirin, which shows a strong antiviral effect on hepatitis $\mathrm{C}$. Ribavirin is known to cause serve anemia and this is the major problem. In the study, NYT was shown to ameliorate the anemia induced by

\section{REFERENCES}

1. Motoo Y, Mouri H, Ohtsubo K, Yamaguchi Y, Watanabe H, Sawabu N. Herbal medicine Ninjinyoeito ameliorates ribavirin-induced anemia in chronic hepatitis C: a randomized controlled trial. World J Gastroenterol. (2005) 11:4013-7. doi: 10.3748/wjg.v11.i26.4013

2. Tanaka K, Sawamura S. Therapeutic effect of a traditional Chinese medicine, ren-shen-yang-rong-tang (Japanese name: Ninjin'yoeito) on nitric oxidemediated lung injury in a mouse infected with murine cytomegalovirus. Int Immunopharmacol. (2000) 6:678-85. doi: 10.1016/j.intimp.2005. 10.011

3. Takano F, Ohta Y, Tanaka T, Sasaki K, Kobayashi K, Takahashi T, et al. Oral administration of Ren-Shen-Yang-Rong-Tang 'Ninjin'yoeito' protects against hematotoxicity and induces immature erythroid progenitor cells in 5fluorouracil-induced anemia. Evid Based Complement Alternat Med. (2009) 6:247-56. doi: 10.1093/ecam/nem080

4. Sato N, Seiwa, C, Komatsu, Y, Kawakita, T, Asou H, Yasukawa A. A Kampo medicine Ninjin-Youei-To promotes recovery from demyelination by FcR $\gamma /$ Fyn signaling. J Traditional Veterinary Med. (2008) 16:3-12. ribavirin in patients with hepatitis C (1). Also, combination of a clinical study with hepatitis $\mathrm{C}$ patients and in vitro studies have shown that NYT and some of its ingredients were effective in the treatment of chronic hepatitis C (69). With regard to hepatocellular carcinoma, one study in cancer patients having advanced hepatocellular carcinoma, together with experimental study with a rat hepatocellular carcinoma model revealed that NYT could enable continuous administration of the anticancer drug sorafenib due to suppression of failure of liver functions and reduction of platelets (70). Lastly, a clinical I/II open-label study with NYT showed that NYT was safe and useful for improvement of fatigue in nonanemic cancer survivors (71).

\section{CONCLUSION}

Since NYT is consist of 12 herbal ingredients and each ingredient has potent improving activities of a variety of symptoms in patients with significant biological activities, the beneficial effect of NYT could be promising. Accordingly, not a few of clinical studies with NYT are now ongoing. In the near future we will recognize and understand the beneficial effects of NYT to patients suffering from many of unpleasant symptoms, owing to the progression of evidence-based scientific researches with NYT.

\section{AUTHOR CONTRIBUTIONS}

In this review, $\mathrm{KM}$ and $\mathrm{YU}$ mainly wrote and summarized the data of NYT. MN, MU and KO contributed to summarize the effects of each ingredient composed of NYT. As a results, all authors have made a substantial, direct and intellectual contribution to the work.

\section{FUNDING}

This work was supported by research grants from AMED under Grant Number 17lk0310037h0001, from Kracie Pharma, Ltd. and from Advanced Brain Research International, Inc.
5. Nomura S, Ishii K, Fujita Y, Azuma Y, Hotta M, Yoshimura Y, et al. Immunotherapeutic effects of Ninjin-youei-to on patients with multiple myeloma. Curr Trends Immunol. (2014) 15:19-27.

6. Takaku S, Shimizu M, Takahashi H. Japanese Kampo medicine ninjin'yoeito synergistically enhances tumor vaccine effects mediated by $\mathrm{CD} 8^{+} \mathrm{T}$ cells. Oncol Lett. (2017) 13:3471-8. doi: 10.3892/ol.2017.5937

7. Suzuki T, Yamamoto A, Ohsawa M, Motoo Y, Mizukami H, Makino T. Effect of ninjin'yoeito and ginseng extracts on oxaliplatin-induced neuropathies in mice. J Nat Med. (2017) 71:757-64. doi: 10.1007/s11418-017-1113-6

8. Egashira T, Takayama F, Komatsu Y. Changes of materials that scavenge 1,1-diphenyl-2-picrylhydrazyl radicals in plasma by per-oral administration of Kampo medicine, Ninjin-yoei-to in rats. J Pharm Pharmacol. (2003) 55:367-71. doi: 10.1211/002235702711

9. Nakada T, Watanabe K, Jin GB, Triizuk K, Hanawa T. Effect of ninjin-youei-to on Th1/Th2 type cytokine production in different mouse strains. Am J Chin Med. (2002) 30:215-23. doi: 10.1142/S0192415X0200034X

10. Fujitsuka N, Asakawa A, Uezono Y, Minami K, Yamaguchi T, Niijima A, et al. Potentiation of ghrelin signaling attenuates cancer anorexia-cachexia and prolongs survival. Transl Psychiatry. (2011) 1:e23. doi: 10.1038/tp.2011.25 
11. Fujitsuka N, Asakawa A, Morinaga A, Amitani MS, Amitani H, Katsuura G, et al. Increased ghrelin signaling prolongs survival in mouse models of human aging through activation of sirtuin1. Mol Psychiatry. (2016) 21:1613-23. doi: $10.1038 / \mathrm{mp} .2015 .220$

12. Uezono Y, Miyano K, Sudo Y, Suzuki M, Shiraishi S, Terawaki K. A review of traditional Japanese medicines and their potential mechanism of action. Curr Pharm Des. (2012) 18:4839-53. doi: 10.2174/138161212803216924

13. Kudoh C, Arita R, Honda M, Kishi T, Komatsu Y, Asou H, et al. Effect of ninjin'yoeito, a Kampo (traditional Japanese) medicine, on cognitive impairment and depression in patients with Alzheimer's disease: 2 years of observation. Psychogeriatrics (2016) 16:85-92. doi: 10.1111/psyg.12125

14. Yabe T, Tuchida H, Kiyohara H, Takeda T, Yamada H. Induction of NGF synthesis in astrocytes by onjisaponins of Polygala tenuifolia, constituents of kampo (Japanese herbal) medicine, Ninjin-yoei-to. Phytomedicine (2003) 10:106-14. doi: 10.1078/094471103321659799

15. Thoenen H. The changing scene of neurotrophic factors. Trends Neurosci. (1991) 14:165-70.

16. Song Q-H, Torizuka K, Iijima K, Watanabe K, Cyong J-C. Effects of Ninjinyoei-to (Rensheng-Yangrong-Tang), a Kampo medicine, on brain monoamine and nerve growth factor contents in mice with olfactory bulb lesions. J Traditional Med. (2001) 18:64-70.

17. McGrath K, Palis J. Ontogeny of erythropoiesis in the mammalian embryo. Curr Top Dev Biol. (2008) 82:1-22. doi: 10.1016/S0070-2153(07)00001-4

18. Inoue T, Kulkeaw K, Muennu K, Tanaka Y, Nakanishi Y, Sugiyama D. Herbal drug ninjin'yoeito accelerates myelopoiesis but not erythropoiesis in vitro. Genes Cells. (2014) 19:432-40. doi: 10.1111/gtc.12143

19. Kyle RA, Therneau TM, Rajkumar SV, Offord JR, Larson DR, Plevak MF, et al. A long-term study of prognosis in monoclonal gammopathy of undetermined significance. N Engl J Med. (2002) 346:564-9. doi: 10.1056/NEJMoa01133202

20. Suzuki T, Yamamoto A, Ohsawa M, Motoo Y, Mizukami H, Makino T. Ninjin'yoeito and ginseng extract prevent oxaliplatin-induced neurodegeneration in PC12 cells. J Nat Med. (2015) 69:531-7. doi: 10.1007/s11418-015-0921-9

21. Matsumoto C, Sekine-Suzuki E, Nyui M, Ueno M, Nakanishi I, Omiya Y, et al. Analysis of the antioxidative function of the radioprotective Japanese traditional (Kampo) medicine, hangeshashinto, in an aqueous phase. J Radiat Res. (2015) 56:669-77. doi: 10.1093/jrr/rrv023

22. Nakae H, Hiroshima Y, Hebiguchi M. Kampo medicines for frailty in locomotor disease. Front Nutr. (2018) 5:31. doi: 10.3389/fnut.2018.00031

23. Ohsawa M, Tanaka Y, Ehara Y, Makita S, Onaka KA (2017). Possibility of simultaneous treatment with the multicomponent drug, Ninjin'yoeito, for anorexia, apathy, and cognitive dysfunction in frail Alzheimer's disease patients: an open-label pilot study. J Alzheimer Dis Rep. 1:229-235. doi: 10.3233/ADR-170026

24. Zhou J, Xu G, Ma S, Li F, Yuan M, Xu H, et al. Catalpol ameliorates high-fat diet-induced insulin resistance and adipose tissue inflammation by suppressing the JNK and NF-kB pathways. Biochem Biophys Res Commun. (2015) 467:853-8. doi: 10.1016/j.bbrc.2015.10.054

25. Jiang B, Shen RF, Bi J, Tian XS, Hinchliffe T, Xia Y. Catalpol: a potential therapeutic for neurodegenerative diseases. Curr Med Chem. (2015) 22:1278-91. doi: 10.2174/0929867322666150114151720

26. Liu C, Ma R, Wang L, Zhu R, Liu H, Guo Y, et al. Rehmanniae radix in osteoporosis: a review of traditional chinese medicinal uses, phytochemistry, pharmacokinetics and pharmacology. J Ethnopharmacol. (2017) 198:351-62. doi: 10.1016/j.jep.2017.01.021

27. Cai Q, Ma T, Tian Y, Li C, Li H. Catalpol inhibits ischemia-induced premyelinating oligodendrocyte damage through regulation of intercellular calcium homeostasis via $\mathrm{Na}^{+} / \mathrm{Ca}^{2+}$ exchanger 3. Int J Mol Sci. (2018) 19:E1925. doi: 10.3390/ijms19071925

28. Du J, Yu Y, Ke Y, Wang C, Zhu L, Qian ZM. Ligustilide attenuates pain behavior induced by acetic acid or formalin. J Ethnopharmacol. (2007) 112:211-4. doi: 10.1016/j.jep.2007.02.007

29. Zhao LX, Jiang BC, Wu XB, Cao DL, Gao YJ. Ligustilide attenuates inflammatory pain via inhibition of NFKB-mediated chemokines production in spina astrocytes. Eur J Neurosci. (2014) 39:1391-402. doi: 10.1111/ejn.12502

30. Qian B, Li F, Zhao LX, Dong YL, Gao YJ, Zhang ZJ. Ligustilide ameliorates inflammatory pain and inhibits TLR4 upregulation in spinal astrocytes following complete Freund's adjuvant peripheral injection. Cell Mol Neurobiol. (2016) 36:143-9. doi: 10.1007/s10571-015-0228-0

31. Liu Y, Jia Z, Dong L, Wang, R, Qiu G. A randomized pilot study of atractylenolide I on gastric cancer cachexia patients. Evid Based Complement Alternat Med. (2008) 5:337-44. doi: 10.1093/ecam/nem031

32. Sadakane C, Muto S, Nakagawa K, Ohnishi S, Saegusa Y, Nahata M, et al. 10Gingerol, a component of rikkunshito, improves cisplatin-induced anorexia by inhibiting acylated ghrelin degradation. Biochem Biophys Res Commun. (2011) 412:506-11. doi: 10.1016/j.bbrc.2011.08.002

33. Wang YZ, Zhang J, Zhao YL, Li T, Shen T, Li JQ, et al. Mycology, cultivation, traditional uses, phytochemistry and pharmacology of Wolfiporia cocos (Schwein.) Ryvarden et Gilb.: a review. J Ethnopharmacol. (2013) 147:265-76. doi: 10.1016/j.jep.2013.03.027

34. Gao AH, Zhang L, Chen X, Chen Y, Xu ZZ, Liu YN, et al. Inhibition of ovarian cancer proliferation and invasion by pachymic acid. Int J Clin Exp Pathol. (2015) 8:2235-41.

35. Chen Y, Lian P, Liu Y, Xu K. Pachymic acid inhibits tumorigenesis in gallbladder carcinoma cells. Int J Clin Exp Med. (2015) 8:17781-8.

36. Wen $\mathrm{H}, \mathrm{Wu} \mathrm{Z}, \mathrm{Hu} \mathrm{H}, \mathrm{Wu}$, Yang $\mathrm{G}, \mathrm{Lu} J$, et al. The antitumor effect of pachymic acid on osteosarcoma cells by inducing PTEN and Caspase 3/7-dependent apoptosis. J Nat Med. (2018) 72:57-63. doi: 10.1007/s11418-017-1117-2

37. Sun KX, Xia HW. Pachymic acid inhibits growth and induces cell cycle arrest and apoptosis in gastric cancer SGC-7901 cells. Oncol Lett. (2018) 16:2517-24. doi: 10.3892/ol.2018.8899

38. Zhong Y-M, Nishijo H, Uwano T, Tamura R, Kawanishi K, Ono T, et al. Red ginseng ameliorated place navigation deficits in young rats with hippocampal lesions and aged rats. Physiol Behav. (2000) 69:511-25. doi: 10.1016/S0031-9384(00)00206-7

39. Zhang G, Liu A, Zhou Y, San X, Jin T, Jin Y. Panax ginseng ginsenoside- $\mathrm{Rg}_{2}$ protects memory impairment via anti-apoptosis in a rat model with vascular dementia. J Ethnopharmacol. (2008) 115:441-8. doi: 10.1016/j.jep.2007. 10.026

40. Zheng $\mathrm{M}$, Xin $\mathrm{Y}$, Li Y, Xu F, Xi X, Guo H, et al. Ginsenosides: A potential neuroprotective agent. Biomed Res Int. (2018) 2018:8174345. doi: $10.1155 / 2018 / 8174345$

41. Kim JH. Pharmacological and medical applications of Panax ginseng and ginsenosides: a review for use in cardiovascular diseases. J Ginseng Res. (2018) 42:264-9. doi: 10.1016/j.jgr.2017.10.004

42. Lee SH, Lee SY, Son DJ, Lee H, Yoo HS, Song S, et al. Inhibitory effect of $2^{\prime}$-hydroxycinnamaldehyde on nitric oxide production through inhibition of NF-кB activation in RAW 264.7 cells. Biochem Pharmacol. (2005) 69:791-9. doi: 10.1016/j.bcp.2004.11.013

43. Singh G, Maurya S, Delampasona MP, Catalan CAN. A comparison of chemical, antioxidant and antimicrobial studies of cinnamon leaf and bark volatile oils, oleoresins and their constituents. Food Chem. Toxicol. (2007) 45:1650-61. doi: 10.1016/j.fct.2007.02.031

44. Kwon HK, Jeon WK, Hwang JS, Lee CG, So JS, Park JA, et al. Cinnamon extract suppresses tumor progression by modulating angiogenesis and the effector function of $\mathrm{CD}^{+} \mathrm{T}$ cells. Cancer Lett. (2009) 278:174-82. doi: $10.1016 /$ j.canlet.2009.01.015

45. Lv C, Yuan X, Zeng HW, Liu RH, Zhang WD. Protective effect of cinnamaldehyde against glutamate-induced oxidative stress and apoptosis in PC12 cells. Eur J Pharmacol. (2017) 815:487-94. doi: 10.1016/j.ejphar.2017.09.009

46. Sedighi M, Nazari A, Faghihi M, Rafieian-Kopaei M, Karimi A, Moghimian M, et al. Protective effects of cinnamon bark extract against ischemia-reperfusion injury and arrhythmias in rat. Phytother. Res. (2018) doi: 10.1002/ptr.6127. [Epub ahead of print].

47. Chen YJ, Huang XB, Li,. Z. X., Yin LL, Chen WQ, Li L. Tenuigenin protects cultured hippocampal neurons against methylglyoxal-induced neurotoxicity. Eur. J. Pharmacol. (2010) 645:1-8. doi: 10.1016/j.ejphar.2010.06.034

48. Chen Y, Huang X, Chen W, Wang N, Li L. Tenuigenin promotes proliferation and differentiation of hippocampal neural stem cells. Neurochem Res. (2012) 37:771-7. doi: 10.1007/s11064-011-0671-3

49. Wang, L.i M, Cao Y, Wang J, Zhang H, Zhou X, et al. Tenuigenin inhibits LPS-induced inflammatory responses in microglia via activating the 
Nrf2-mediated HO-1 signaling pathway. Eur J Pharmacol. (2017) 809:196202. doi: 10.1016/j.ejphar.2017.05.004

50. Tsai TY, Wu SN, Liu YC, Wu AZ, Tsai YC. Inhibitory action of L-type Ca2+ current by paeoniflorin, a major constituent of peony root, in NG108-15 neuronal cells. Eur J Pharmacol. (2005) 523:16-24. doi: 10.1016/j.ejphar.2005.08.042

51. Lee KK, Omiya Y, Yuzurihara M, Kase Y, Kobayashi H. Antispasmodic effect of shakuyakukanzoto extract on experimental muscle cramps in vivo: role of the active constituents of Glycyrrhizae radix. J Ethnopharmacol. (2013) 145:286-93. doi: 10.1016/j.jep.2012.11.005

52. Wang Z, Shen L, Li X, Shu X, Shan B, Zhang L, et al. Pain-relieving effect of a compound isolated from white peony root oral liquid on acute radiation-induced esophagitis. Mol Med Rep. (2013) 7:1950-4. doi: $10.3892 / \mathrm{mmr} .2013 .1427$

53. Seiwa C, Yamamoto M, Tanaka K, Fukutake M, Ueki T, Takeda S, et al. Restoration of FcRgamma/Fyn signaling repairs central nervous system demyelination. J Neurosci Res. (2007) 85:954-66. doi: 10.1002/jnr.21196

54. Sato N, Seiwa C, Uruse M, Yamamoto M, Tanaka K, Kawakita T, et al. Administration of chinpi, a component of the herbal medicine ninjin-youeito, reverses age-induced demyelination. Evid Based Complement Alternat Med. (2011) 2011:617438. doi: 10.1093/ecam/neq001

55. Roohbakhsh A, Parhiz H, Soltani F, Rezaee R, Iranshahi M. Neuropharmacological properties and pharmacokinetics of the citrus flavonoids hesperidin and hesperetin-a mini-review. Life Sci. (2014) 113:1-6. doi: 10.1016/j.lfs.2014.07.029

56. Justin Thenmozhi A, William Raja TR, Manivasagam T, Janakiraman U, Essa MM. Hesperidin ameliorates cognitive dysfunction, osidative stress and apoptosis against aluminium chloride induced rat model of Alzheimer's disease. Nutr Neurosci. (2017) 20:360-8. doi: 10.1080/1028415X.2016.1144846

57. Yamauchi T, Kamon J, Waki H, Terauchi Y, Kubota N, Hara K, et al. The fatderived hormone adiponectin reverses insulin resistance associated with both lipoatrophy and obesity. Nat Med. (2001) 7:941-936. doi: 10.1038/90984

58. Kadowaki T, Yamauchi T, Kubota N, Hara K, Ueki K, Tobe K. Adiponectin and adiponectin receptors in insulin resistance, diabetes, and the metabolic syndrome. J Clin Invest. (2006) 116:1784-92. doi: 10.1172/JCI29126

59. Na D, Liu FN, Miao ZF, Du ZM, Xu HM. Astragalus extract inhibits destruction of gastric cancer cells to mesothelial cells by anti-apoptosis. World J Gastroenterol. (2009) 15:570-7. doi: 10.3748/wjg.15.570

60. Xu A, Wang H, Hoo RL, Sweeney G, Vanhoutte PM, Wang Y, et al. Selective elevation of adiponectin production by the natural compounds derived from a medicinal herb alleviates insulin resistance and glucose intolerance in obese mice. Endocrinology. (2009) 150:625-33. doi: 10.1210/en.2008-0999

61. Hosseinzadeh H, Nassiri-Asl M. Pharmacological Effects of Glycyrrhiza spp. and Its Bioactive Constituents: Update and Review. Phytother Res. (2015) 29:1868-86. doi: 10.1002/ptr.5487

62. Dastagir G, Rizvi MA. Glycyrrhiza glabra L. (Liquorice) Pak J Pharm Sci. (2016) 29:1727-33.
63. Moon PD, Jeong HJ, Kim HM. Effects of schizandrin on the expression of thymic stromal lymphopoietin in human mast cell line HMC-1. Life Sci. (2012) 91:384-8. doi: 10.1016/j.lfs.2012.08.009

64. Kim YJ, Yoo SR, Chae CK, Jung UJ, Choi MS. Omija fruit extract improves endurance and energy metabolism by upregulating PGC- $1 \alpha$ expression in the skeletal muscle of exercised rats. J Med Food. (2014) 17:28-35. doi: 10.1089/jmf.2013.3071

65. Araki R, Hiraki Y, Nishida S, Inatomi Y, Yabe T. Gomisin N ameliorates lipopolysaccharide-induced depressive-like behaviors by attenuating inflammation in the hypothalamic paraventricular nucleus and central nucleus of the amygdala in mice. J Pharmacol Sci. (2016) 132:138-44. doi: 10.1016/j.jphs.2016.09.004

66. Lee JY, Kim KY, Shin KY, Won BY, Jung HY, Suh YH. Effects of BT-11 on memory in healthy humans. Neurosci Lett. (2009) 454:111-4. doi: 10.1016/j.neulet.2009.03.024

67. Shin KY, Lee JY, Won BY, Jung HY, Chang KA, Koppula S, et al. BT-11 is effective for enhancing cognitive functions in the elderly humans. Neurosci Lett. (2009) 465:157-9. doi: 10.1016/j.neulet.2009. 08.033

68. Hsiao PJ, Lin KS, Chiu CC, Chen HW, Huang JS, Kao SY, et al. Use of traditional Chinese medicine (Ren Shen Yang Rong Tang) against microinflammation in hemodialysis patients: An open-label trial. Complement Ther Med. (2015) 23:363-71. doi: 10.1016/j.ctim.2015.03.002

69. Cyong J-C, Ki SM, Iijima K, Kobayashi T, Furuya M. Clinical and pharmacological studies on liver diseases treated with Kampo herbal medicine. Am J Chin Med. (2000) 28:351-60. doi: 10.1142/S0192415X00000416

70. Kaibori M, Ishizaki M, Matsui K, Kwon M, Imai R, Watanabe S, et al. Sorafenib alone versus a combination of sorafenib and ninjin'yoeito for the treatment of patients with advanced hepatocellular carcinoma: a retrospective study and pharmacological study in rats. J Trad Med. (2013) 30:221-8. doi: $10.11339 /$ jtm.30.221

71. Xu Y, Chen Y, Li P, Wang XS. Ren Shen Yangrong Tang for fatigue in cancer survivors: A phase I/II open-label study. J Altern Complement Med. (2015) 21:281-7. doi: 10.1089/acm.2014.0211

Conflict of Interest Statement: The authors declare that the research was conducted in the absence of any commercial or financial relationships that could be construed as a potential conflict of interest.

Copyright (c) 2018 Miyano, Nonaka, Uzu, Ohshima and Uezono. This is an openaccess article distributed under the terms of the Creative Commons Attribution License (CC BY). The use, distribution or reproduction in other forums is permitted, provided the original author(s) and the copyright owner(s) are credited and that the original publication in this journal is cited, in accordance with accepted academic practice. No use, distribution or reproduction is permitted which does not comply with these terms. 